\title{
The 5\% Lidocaine-Medicated Plaster: Its Inclusion in International Treatment Guidelines for Treating Localized Neuropathic Pain, and Clinical Evidence Supporting its Use
}

Ralf Baron · Massimo Allegri · Gerardo Correa-Illanes • Guy Hans •

Michael Serpell · Gerard Mick · Victor Mayoral

Received: October 3, 2016 / Published online: November 7, 2016

(C) The Author(s) 2016. This article is published with open access at Springerlink.com

\section{ABSTRACT}

When peripheral neuropathic pain affects a specific, clearly demarcated area of the body, it may be described as localized neuropathic pain (LNP). Examples include postherpetic neuralgia and painful diabetic neuropathy, as well as post-surgical and post-traumatic pain. These conditions may respond to topical treatment, i.e., pharmaceutical agents acting locally on the peripheral nervous system, and the topical

Enhanced content To view enhanced content for this article go to www.medengine.com/Redeem/

3417F0600172E875.

R. Baron $(\varangle)$

Division of Neurological Pain Research and Therapy,

Department of Neurology,

Christian-Albrechts-Universität zu Kiel, Kiel,

Germany

e-mail: r.baron@neurologie.uni-kiel.de

M. Allegri

Pain Therapy Service, Azienda Ospedaliera

Universitaria Parma Hospital, Parma, Italy

G. Correa-Illanes

Rehabilitation Department, Hospital del Trabajador de Asociación Chilena de Seguridad, Santiago, Chile

G. Hans

Multidisciplinary Pain Centre, Antwerp University

Hospital, Edegum, Belgium route offers advantages over systemic administration. Notably, only a small fraction of the dose reaches the systemic circulation, thereby reducing the risk of systemic adverse effects, drug-drug interactions and overdose. From the patient's perspective, the analgesic agent is easily applied to the most painful area(s). The 5\% lidocaine-medicated plaster has been used for several years to treat LNP and is registered in approximately 50 countries. Many clinical guidelines recommend this treatment modality as a first-line option for treating LNP, particularly in frail and/or elderly patients and those receiving multiple

\section{Serpell}

University Department of Anaesthesia, Pain Research Office, Gartnavel General Hospital, Glasgow, Scotland, UK

\section{G. Mick}

Centre for Pain Evaluation and Treatment, University Neurological Hospital, Lyons, France

\section{Mayoral}

Anaesthesiology Department, Hospital Universitario de Bellvitge, El Hospitalet de Llobregat, 08907 Barcelona, Spain 
medications, because the benefit-to-risk ratios are far better than those of systemic analgesics. However, some guidelines make only a weak recommendation for its use. This paper considers the positioning of the 5\% lidocaine-medicated plaster in international treatment guidelines and how they may be influenced by the specific criteria used in developing them, such as the methodology employed by randomized, placebo-controlled trials. It then examines the body of evidence supporting use of the plaster in some prevalent LNP conditions. Common themes that emerge from clinical studies are: (1) the excellent tolerability and safety of the plaster, which can increase patients' adherence to treatment, (2) continued efficacy over long-term treatment, and (3) significant reduction in the size of the painful area. On this basis, it is felt that the 5\% lidocaine-medicated plaster should be more strongly recommended for treating LNP, either as one component of a multimodal approach or as monotherapy.

Keywords: $5 \%$ lidocaine-medicated plaster; Allodynia; Ease of use; Efficacy; Guidelines; Localized neuropathic pain; Long-term safety; Postherpetic neuralgia; Quality of life; Reviews

\section{INTRODUCTION}

The 5\% lidocaine-medicated plaster has been used for several years to treat localized neuropathic pain (LNP) and reviews of published studies support its use in this indication [1, 2]. Topical application offers a number of advantages over systemic administration. For example, systemic levels of topical analgesic agents are low-with 5\% lidocaine-medicated plasters, only $3 \% \pm 2 \%$ of the dose reaches the systemic circulation [3] so the risk of drug-drug interactions, systemic side effects and overdose is much reduced [4]. This increased safety margin is important because the response to prescribed medication can vary widely between patients, often as a result of polymorphisms [5], and it is particularly relevant for vulnerable patients such as the elderly and those receiving polypharmacy for multiple co-morbidities. From a practical aspect, the topical route offers simple site-specific delivery by the patients themselves to the most painful areas, without the need for dose titration [6], and the act of application may increase the placebo element of analgesia [7].

To date, the 5\% lidocaine-medicated plaster (Versatis $^{\circledR}$, Grünenthal $\mathrm{GmbH}$, Aachen, Germany) has been registered in approximately 50 countries around the world. In the majority of these countries, it is licensed only for relieving neuropathic pain caused by postherpetic neuralgia (PHN), but in 11 Latin American countries it has been approved for treating LNP. The total cumulative patient exposure to $5 \%$ lidocaine-medicated plaster since marketing authorization was first obtained in 1999 has now reached approximately 23 million patients. Its efficacy and safety in treating PHN have led to widespread use in other LNP syndromes, including diabetic distal polyneuropathy, post-surgical, and post-traumatic pain [1].

A number of researchers and reviewers have recommended the lidocaine plaster as a first-line option for treating LNP [2, 8-15], because the benefit-to-risk ratios are far better than those of systemic analgesic agents $[16,17]$. At the present time, the management of patients with neuropathic pain is often inadequate $[18,19]$, and many patients are not satisfied with their treatment $[20,21]$. The objective of this article is to examine the 
inclusion of the $5 \%$ lidocaine-medicated plaster in international treatment guidelines and the body of evidence currently supporting its use, so that this pharmacological option may be considered more often by clinicians treating patients with LNP.

\section{Compliance with Ethics Guidelines}

This article is based on previously conducted studies and does not involve any new studies of human or animal subjects performed by any of the authors.

\section{THE 5\% LIDOCAINE-MEDICATED PLASTER}

Lidocaine is a voltage-gated sodium channel inhibitor, which is understood to act by blocking abnormally functioning (sensitized) Nav1.7 and Nav1.8 sodium channels in the dermal nociceptors of A delta and C fibers, thereby reducing the number of ectopic discharges [22-24]. However, it is also effective in patients where nociceptive function is impaired [25]. This is probably due to an inhibitory effect on inflammatory processes, as lidocaine has been shown to regulate $\mathrm{T}$ cell activity and suppress the production of nitric oxide $[26,27]$. Another probable mechanism is direct activation of the TRP (transient receptor potential) channels TRPV1 and TRPA1 expressed in nociceptive sensory neurons. This produces analgesia by membrane depolarization, reducing the electrical activity in TRP-containing nerves [28].

Each $5 \%$ lidocaine-medicated plaster measures $10 \times 14 \mathrm{~cm}$ and consists of a white hydrogel adhesive containing lidocaine $(700 \mathrm{mg}, 5 \% \mathrm{w} / \mathrm{w})$ attached to a non-woven polyethylene terephthalate backing [29]. The plaster is applied once daily to intact, dry, non-irritated skin and worn for a maximum of $12 \mathrm{~h}$. Up to three plasters may be applied simultaneously, depending upon the size of the painful area, and the subsequent plaster-free period must be at least $12 \mathrm{~h} \mathrm{[29].} \mathrm{Where}$ appropriate, plasters may be cut to match the shape of the painful area. Application provides mechanical protection and a sensation of immediate cooling (the 'patch' effect) [30]. Steady-state plasma concentrations of lidocaine are reached within the first 4 days [29], but the maximum concentration remains far below clinically relevant levels even when the recommended dose is exceeded [31]. After extensive metabolism in the liver, mainly by $\mathrm{N}$-alkylation, the excretion of lidocaine and its metabolites is primarily via the kidneys [29]. Less than $10 \%$ of the lidocaine dose is excreted unchanged [29]. The elimination half-life in healthy individuals is $7.6 \mathrm{~h}$, but may be delayed in the presence of cardiac, renal, or hepatic insufficiency [29]. Treatment should be reassessed at regular intervals to determine whether the number of plasters can be reduced, or the plaster-free period extended [29].

Treatment with the lidocaine plaster is generally well tolerated and markedly improves patients' quality of life [1]. The most frequently reported adverse events are mild-to-moderate reactions at the application site, including erythema, pruritus, rash, burning sensation, edema, and other skin reactions $[9,17,32]$. These adverse events are generally transient and resolve without further treatment once the plaster is removed [17]. Furthermore, the excellent safety profile continues with long-term treatment. In an open-label study lasting up to 4 years, medication was rated as 'good' or better by $88 \%$ of patients and only $18.6 \%$ experienced adverse events that could be 
related to their treatment [33]. Another group of patients with chronic refractory neuropathic pain caused by postherpetic neuralgia was surveyed after using the lidocaine plaster daily for a mean period of 7.6 years [34]. Using an 11-point numerical rating scale (NRS) on which a score of +5 represented 'Extremely Satisfied' and -5 'Extremely Dissatisfied', mean satisfaction with pain relief was rated at +3.8 , mean overall satisfaction at +4.0 , and $75 \%$ of the patients reported having had no adverse events [34].

\section{NEUROPATHIC PAIN AND LNP}

Neuropathic pain is defined by the International Association for the Study of Pain (IASP) as "pain arising as a direct consequence of a lesion or disease affecting the somatosensory system" [35, 36]. Population-based surveys in the United Kingdom and France have found the prevalence of pain with predominantly neuropathic characteristics to be $8 \%$ and $6.9 \%$, respectively $[37,38]$. Currently, expert opinion is that neuropathic pain arises from damage to somatosensory small fibers rather than non-nociceptive pathways $[39,40]$. The origin may be central or peripheral, and neuropathic pain is a feature of many different conditions. The most common symptoms are continuous burning pain, paroxysmal 'electric shock' or lancinating pain, and allodynia [40-42]. Burning pain reflects spontaneous hyperactivity in nociceptive C-fiber pathways, which may originate from (1) 'irritable' nociceptors (i.e., that have increased excitability as a result of peripheral sensitization, mainly produced by changes in voltage-gated sodium channel expression [43]), (2) hyperexcitable regenerating nerve sprouts, or (3) denervated central neurons [40]. Paroxysmal pain probably arises from high-frequency ectopic bursts generated in demyelinated, non-nociceptive $A \beta$ fibers [40]. Mechanical dynamic allodynia is mediated by non-nociceptive $A \beta$ fibers activating central pain pathways, but 'irritable' C-nociceptors probably contribute to the maintenance of allodynia and to central sensitization in peripheral neuropathies [40].

Evidence suggests that herpes zoster and peripheral nerve traumas are the most frequent causes of peripheral neuropathic pain, whereas stroke, multiple sclerosis and spinal cord injury are the major causes of central neuropathic pain [44-47]. The negative impact upon functioning and quality of life is profound [48, 49]. Studies have demonstrated that neuropathic pain is more severe than non-neuropathic pain [50], it is associated with an excessive psychosocial burden compared with nociceptive pain, and it can induce more intense psychological comorbidity than other types of chronic pain $[48,50,51]$.

Although neuropathic pain may be widely distributed, in approximately $60 \%$ of patients it affects a specific, clearly demarcated area of the body [52] and may be described as 'localized neuropathic pain' (LNP). In order to help clinicians distinguish LNP from other types of neuropathic pain, a body of experts proposed the following definition of LNP in 2010, based upon the IASP definition of neuropathic pain and 13 reference articles: 'A type of peripheral neuropathic pain that is characterized by consistent and circumscribed area(s) of maximum pain associated with abnormal sensitivity of the skin and/or spontaneous symptoms characteristic of neuropathic pain, for example, burning pain' [52]. By identifying patients with LNP-who may benefit from topical treatment-this definition facilitates an 
evidence-based approach to the management of neuropathic pain. It should be pointed out that topical treatment refers to pharmaceutical agents that act locally on the peripheral nervous system, in contradistinction to medications such as buprenorphine and fentanyl that may be applied to the skin but which exert their effect on the CNS following transdermal systemic absorption [7].

\section{LNP TREATMENT GUIDELINES-POSITIONING OF THE 5\% \\ LIDOCAINE-MEDICATED PLASTER}

Most clinical evidence on the efficacy of the 5\% lidocaine-medicated plaster-and most guidelines-relate to the treatment of PHN, owing to its being more widely licensed for this condition, and the comparatively recent definition of LNP.

For its 2004 guidelines, reaffirmed in 2010, the Quality Standards Subcommittee of the American Academy of Neurology examined 51 articles on therapies for treating PHN [53]. The following parameters were calculated for each study using intent-to-treat analysis: absolute risk reduction (proportion of control group with benefit minus proportion of treated group with benefit); number needed to treat (NNT) for adequate pain relief; 95\% confidence interval for the NNT; and number needed to harm $(\mathrm{NNH})$. A score was then determined for each therapy based upon the quality of the studies (e.g., Class I evidence was provided by a prospective, randomized, controlled clinical trial with masked outcome assessment in a representative population). On the basis of these criteria, the $5 \%$ lidocaine-medicated plaster was placed in the top treatment category for PHN, along with gabapentin, oxycodone or morphine sulphate, pregabalin and tricyclic antidepressants (TCAs) [53]. These were all considered to offer medium-to-high efficacy, good strength of evidence supporting their use, and a low level of side effects [53].

Evidence-based recommendations for the treatment of neuropathic pain were first published by the Neuropathic Pain Special Interest Group (NeuPSIG) of the IASP in 2007, following a consensus meeting [8]. Initially, relevant publications were identified through Medline literature searches (1966-2007), reference lists of published articles and book chapters, and personal knowledge of the authors. This published material, along with unpublished data and the authors' clinical experience, was then used to evaluate various medications in terms of efficacy, safety, tolerability, drug interactions, ease of use, and impact on health-related quality of life [8]. Having demonstrated efficacy in PHN and diverse peripheral neuropathic pain conditions, the $5 \%$ lidocaine-medicated plaster was recommended as a first-line treatment for peripheral neuropathic pain, but not for central neuropathic pain [8]. These recommendations were later reviewed and updated by NeuPSIG in 2010, after more clinical trials had been completed [11]. Group members concluded that adherence to the existing guidelines should be improved for the time being, while additional randomized, controlled trials directly comparing neuropathic pain medications were conducted and alternative evaluative strategies were developed [11].

Later in 2010, recommendations on the pharmacological management of neuropathic pain were published by Attal et al. [54]. These recommended topical lidocaine as a first-line treatment for PHN, commenting on its excellent tolerability and noting that all 
recommendations for the pharmacological treatment of neuropathic pain at that time proposed antiepileptics (gabapentin or pregabalin), TCAs, serotonin-noradrenaline reuptake inhibitors (SNRIs) or topical lidocaine as the first line of treatment for neuropathic pain in general, or for specific neuropathic pain conditions [54].

Narrower terms of reference were used by the European Federation of Neurological Societies (EFNS) Task Force to produce its guidelines, which were first published in 2006 [55] and updated in 2010 [13]. The Cochrane Database and then Medline were searched for relevant studies, which were subsequently classified according to the etiological condition investigated. All EFNS Class I and Class II randomized controlled trials were assessed, with lower class studies being considered in conditions for which there were no top level studies. NNT values and their corresponding 95\% confidence intervals were calculated in order to provide information about the overall efficacy of analgesic agents $[13,55]$. The earlier guidelines considered that there was insufficient evidence to confirm the efficacy of the lidocaine plaster, but stated that it may be preferred to other agents when treating PHN-particularly in patients with allodynia and a small area of pain-because of its excellent tolerability [55]. The inclusion of additional trials in the 2010 update provided some good evidence of efficacy, although trial results were inconsistent. Consequently, the updated guidelines stated that the 5\% lidocaine-medicated plaster may be considered a first-line treatment in the elderly, particularly if there are concerns regarding the CNS side effects of oral medications [13].

A new, more rigorous and generally accepted methodology (GRADE-Grading of Recommendations Assessment, Development, and Evaluation) was adopted for the 2015 revision of the NeuPSIG guidelines [56]. GRADE classifies the quality of evidence as high, moderate, or low according to various factors, including the risk of bias, precision of estimates, consistency of results, and directness of evidence [57]. A strong recommendation for use is given only when the benefits of an intervention clearly outweigh the undesirable effects [57]. A systematic review and meta-analysis were conducted of randomized, double-blind studies of pharmacotherapy for neuropathic pain, as well as unpublished trials retrieved from ClinicalTrials.gov and the Web sites of pharmaceutical companies [56]. The NNT for $50 \%$ pain relief was used as the primary outcome measure, and publication bias was assessed. Stringency of the GRADE criteria meant that only three trials of the lidocaine plaster were included, so that the quality of assessed evidence was low. Thus, only a weak recommendation for use was made, as a second-line treatment for peripheral neuropathic pain with presumed local pain generator (such as PHN), post-traumatic painful neuropathies and polyneuropathies [56]. However, it was acknowledged that in certain circumstances, such as concern about side effects or the safety of first-line options, particularly in frail and elderly patients, the 5\% lidocaine-medicated plaster might be a first-line option [56].

Also in 2015, an international advisory board of pain specialists, selected on the basis of their research activity and considerable clinical experience, met to develop a treatment guidance algorithm specifically for LNP, to be used in the primary care setting [15]. It was generally felt that existing guidelines were of limited use in determining treatment for LNP, because most do not specifically address this condition-or even recognize it as a specific 
entity-and recommendations of the different guidelines are not consistent [15]. Board members strongly agreed that the first-line treatment-irrespective of age-should be a topical analgesic agent in most cases unless there are contraindications such as broken, atrophic, or infected skin-essentially because the topical route offers a far better safety profile $[16,17]$ and there is evidence that it can reduce the size of the painful area [58-60]. Factors influencing the choice of topical agent should include ease of application and use, patient preference, and availability [15], but the 5\% lidocaine-medicated plaster currently has the most evidence supporting its use in treating LNP.

\section{SUPPORTING EVIDENCE IN THE TREATMENT OF LNP}

\section{Postherpetic Neuralgia (PHN)-Efficacy}

$\mathrm{PHN}$ is a common complication of herpes zoster infection or 'shingles', which may persist for months or even years. Patients experience persistent pain, often intense, which has been described as burning, stabbing, shooting, or throbbing. Tactile allodynia (pain evoked by lightly touching the skin) is present in $\geq 70 \%$ of patients [61]. This symptom is associated with significant loss of function and reduced quality of life, particularly in the elderly, and is highly resistant to treatment $[62,63]$. Although the number of randomized, controlled studies is limited, the efficacy of the 5\% lidocaine-medicated plaster in PHN treatment has been demonstrated in many open-label studies and case series, and is well established $[1,2]$.

A 2009 paper by Garnock-Jones and Keating reviewed the clinical evidence for using the lidocaine plaster to treat PHN, focusing on fully published studies [9]. Two randomized, double-blind, placebo-controlled trials had an initial open-label phase before responders were randomized to comparative treatment for a period of up to 2 weeks [64, 65]. The primary endpoint was the time to exit from treatment as a result of lack of efficacy, defined as a drop of $\geq 2$ points on the Visual Rating Scale (VRS) of pain relief from baseline $[64,65]$. In one study, the time to exit was significantly different between the groups for the intention-to-treat (ITT) population ( $>14$ days for lidocaine vs. 3.8 days for placebo; $p<0.001$ ) [64]. In the other study, this difference did not reach significance in the ITT population, but did in the per-protocol (PP) population (14.0 vs. 6.0 days; $p<0.0398$ ) [65]. When compared to pregabalin in a 4-week, open-label, randomized, non-inferiority study, more patients with PHN in the PP population responded to topical lidocaine than to pregabalin capsules (62.2 vs. $46.5 \%$ ), and also experienced a more marked reduction in 'painful' and 'extremely painful' allodynia (58\% at baseline to $25 \%$ at endpoint vs. $63 \%$ at baseline to $41 \%$ at endpoint) [16]. In addition, the consumption of rescue medicine was reduced by half in the patients treated with topical lidocaine, but no change was observed in those receiving pregabalin [66]. The authors of the review paper concluded that the 5\% lidocaine-medicated plaster is a useful first-line option for treating patients with PHN [9].

A 2011 systematic review compared the 5\% lidocaine-medicated plaster for the relief of PHN with other relevant interventions and placebo [67]. Six databases were searched up to May 2010 and a network meta-analysis conducted. When multiple interventions are used for the same disease and outcomes, this technique employs indirect evidence to gain certainty about all treatment comparisons, thereby 
allowing parameters such as efficacy and safety-which have not been investigated in head to head clinical trials-to be compared [68]. This network meta-analysis included 20 unique studies (32 publications). The results suggest that the 5\% lidocaine-medicated plaster and gabapentin provide similar levels of pain relief and, furthermore, that the lidocaine plaster is more effective than pregabalin or high-dosage topical capsaicin [67].

An open-label, Phase III study carried out in 12 European countries assessed the efficacy of the lidocaine plaster over a period of up to 4 years [33]. Patients aged $>50$ years with PHN lasting $\geq 3$ months and a baseline pain intensity of at least 4 on an 11-point NRS (0-10) received the lidocaine plaster in addition to any existing medication. Pain relief was measured using a six-point VRS $(1=$ worse pain to $6=$ complete relief) according to each patient's recollection of pain intensity over the previous week. A mean pain relief score of 4.3 was achieved after 6 weeks of treatment with the 5\% lidocaine-medicated plaster-equivalent to between 'moderate' and 'a lot' on the VRSand this level was maintained throughout the 1-year main study and the 3-year extension phase [33]. The Patient Global Impression of Change (PGIC) was assessed during the extension phase; the proportion of patients rating it as 'much improved' or 'very much improved' was $71 \%$ at 24 months and $93 \%$ at 36 months [33].

A recent study by Casale et al. comprised a case series of elderly patients with PHN who were receiving one or more systemic drugs, but whose pain was inadequately controlled or who had good pain control but were experiencing severe side effects [60]. The 5\% medicated plaster was prescribed in addition to their systemic medication and they were followed up for 3 months. Effective pain relief began as early as 2 weeks after the commencement of topical treatment and steadily increased, reaching $52.00 \pm 23.87 \%$ after 4 weeks and $60.00 \pm 18.70 \%$ after 12 weeks [60]. Notably, the area of allodynia progressively decreased from baseline, with a reduction of $46 \%$ after 1 month $(p=0.129)$ and $66 \%$ after 3 months $(p=0.02)$, enabling patients to apply fewer and smaller plasters [60]. The authors suggest these results indicate a possible role for long-term treatment with the lidocaine plaster to reduce the painful area affected by LNP, although further research is needed [60].

\section{Postherpetic Neuralgia (PHN)-Safety}

The incidence of PHN increases with age and is uncommon in patients younger than 60 years [69]. Many are already being treated for co-morbidities with a variety of medications, so minimizing the risk of adverse events for these patients is particularly important. The 5\% lidocaine-medicated plaster is the only $\mathrm{PHN}$ treatment for which safety and efficacy data on clinical use of up to 4 years duration is available $[17,33]$.

In a prospective, open-label, non-randomized study in 332 patients with PHN, there were no serious systemic ADRs, and no ADRs relating to an organ class other than the skin affected more than $10 \%$ of the patients [70]. In a comparison study with pregabalin by Baron et al., five patients in the lidocaine group reported five ADRs, of which three were mild or moderate application-site reactions [16]. By contrast, 25 patients in the pregabalin group reported 82 ADRs, and 22 of these were of severe intensity [16].

The safety and tolerability of this treatment has been summarized in a recent review of both published material and unpublished clinical data [17]. In a pooled analysis of three clinical 
trials that included 394 subjects with a mean age of $>70$ years, 78 patients experienced 131 ADRs [17]. None was considered to be serious and $83 \%$ were related to the skin, with application site erythema and pruritus being reported most frequently [17]. A separate study in elderly patients with PHN (mean age 70 years) found that cognitive integrity was maintained in those treated with the 5\% lidocaine-medicated plaster, whereas those receiving systemic medication were significantly impaired in terms of vigilance, decision-making, and semantic memory [71].

For most studies, the rate of premature discontinuation of treatment with the lidocaine plaster because of ADRs is less than $5 \%$ [17]. Post-marketing experience has revealed that more serious reactions such as open wounds, hypersensitivity, and anaphylactic shock do occur, but are extremely rare $(<1 /$ 10,000 patients) [29].

\section{Painful Diabetic Neuropathy (DN)}

Diabetic polyneuropathy is the most common complication of type 1 and type 2 diabetes mellitus, affecting as many as 50\% of patients [72]. It typically manifests as 'burning' pain associated with paraesthesia/dysesthesia and/or allodynia [73]. The effect on physical and mental quality of life is profound, even after adjusting for pain intensity, yet one survey found that only $28 \%$ of diabetic patients with neuropathic pain were receiving a treatment recommended for it [73].

When the 5\% lidocaine-medicated plaster was added to existing treatment for DN in an open-label study, it was shown to produce significant improvements in Brief Pain Inventory (BPI) scores for pain intensity and pain relief after 2 weeks (Table 1) [74]. These were accompanied by significant reductions of pain interference with general activity, mood, walking ability, normal work, relationships with others, sleep, and enjoyment of life [74]. In another study, the treatment effect was evaluated according to changes in four composite measures of the Neuropathic Pain Scale (NPS-10, NPS-4, NPS-8, and NPS-non-allodynia) over a period of 2 weeks (Table 1) [75]. Adding the lidocaine plaster significantly improved all four composite measures $(p<0.001)$ and was well tolerated, with no reports of serious adverse events or adverse drug interactions [75].

The 5\% lidocaine-medicated plaster was used as monotherapy in the comparative study with pregabalin previously mentioned, and results for the diabetic polyneuropathy population (Table 1) differed slightly from those for PHN patients [16]. The response rates to treatment (defined as a reduction of $\geq 2$ from baseline or an absolute score of $\leq 4$ on the NRS in the PP population at the end of the treatment period) were similar in the lidocaine and pregabalin groups (67 vs. 69\%, respectively) [16]. Reductions in the severity of allodynia were also comparable, but the EuroQol-5 Dimension (EQ-5D) quality of life index showed a greater improvement in the lidocaine group $(0.13 \pm 0.2)$ than in the pregabalin group $(0.06 \pm 0.2)$ [16].

A 2010 systematic review specifically investigated the role of the 5\% lidocaine-medicated plaster in painful diabetic peripheral neuropathy [12]. Six databases were searched and 23 studies (38 publications) were included. In order to compare the lidocaine plaster with other relevant treatments for which direct comparative studies were not available, quantitative methods for data synthesis were used and a network meta-analysis conducted [12]. The results showed that all the interventions examined $\quad(5 \%$ lidocaine-medicated plaster, amitriptyline, 
Table 1 Studies involving use of the 5\% medicated plaster to treat painful diabetic neuropathy

\begin{tabular}{|c|c|c|c|c|c|}
\hline Authors and study design & $\begin{array}{l}\text { No. of } \\
\text { patients }\end{array}$ & $\begin{array}{l}\text { Mean } \\
\text { baseline } \\
\text { pain rating }\end{array}$ & $\begin{array}{l}\text { No. of } \\
\text { plasters } \\
\text { (daily) }\end{array}$ & $\begin{array}{l}\text { Treatment } \\
\text { duration }\end{array}$ & $\begin{array}{l}\text { Main efficacy outcomes (end of } \\
\text { observation) }\end{array}$ \\
\hline $\begin{array}{l}\text { White et al. [74]. Open-label pilot } \\
\text { study, add-on to gabapentin } \\
\text { treatment regimens }\end{array}$ & 49 & $6.3(\mathrm{BPI})^{\mathrm{a}}$ & $\begin{array}{l}2.5 \\
(24 \mathrm{~h} \\
\text { on) }\end{array}$ & 2 weeks & $\begin{array}{l}\text { Pain intensity and pain relief scores } \\
\text { improved }(p<0.0001)^{a} \text {. Quality } \\
\text { of life improved for all BPI } \\
\text { domains }(p<0.05)\end{array}$ \\
\hline $\begin{array}{l}\text { Argoff et al. [75]. Prospective, } \\
\text { open-label pilot study, add-on }\end{array}$ & 41 & $\mathrm{~N} / \mathrm{A}$ & $\begin{array}{l}2.7 \\
(24 \mathrm{~h} \\
\text { on })\end{array}$ & 2 weeks & $\begin{array}{l}\text { Improvement in all composite } \\
\text { measures of the NPS }(p<0.001)\end{array}$ \\
\hline $\begin{array}{l}\text { Baron et al. [16]. Phase III, } \\
\text { randomized, open-label, } \\
\text { non-inferiority study, } \\
\text { monotherapy, } \\
\text { comparator = pregabalin up to } \\
600 \mathrm{mg} / \text { day }\end{array}$ & 105 & $\begin{array}{l}6.9 \text { (NRS } \\
\text { over } \\
\text { preceding } \\
3 \text { days) }\end{array}$ & $\begin{array}{l}\text { Up to } 4 \\
\text { (up to } \\
12 \mathrm{~h} \\
\text { on) }\end{array}$ & 4 weeks & $\begin{array}{l}\text { Treatment response (reductions in } \\
\text { pain intensity and allodynia } \\
\text { severity) comparable in both } \\
\text { groups, greater improvements in } \\
\text { quality of life (EQ-5D) in } \\
\text { patients receiving lidocaine } \\
\text { plaster }\end{array}$ \\
\hline
\end{tabular}

All data are expressed as the mean unless otherwise stated. For studies with a control group, only lidocaine data are shown $B P I$ brief pain inventory, EQ-5D EuroQol-5 dimension QoL index, $N / A$ not available, NPS neuropathic pain scale, NRS numerical rating scale

${ }^{a}$ Includes data from patients with postherpetic neuralgia and low back pain

capsaicin, gabapentin, pregabalin) were more effective than placebo, and the effects of the lidocaine plaster on pain were comparable to all the other interventions [12]. In addition, the results suggest that topical treatments are associated with fewer and less clinically significant adverse events than systemic agents [12]. The authors concluded that in view of its comparable efficacy and greater tolerability, the 5\% lidocaine-medicated plaster should be considered as a first-line treatment for diabetic peripheral neuropathy, but the small numbers, limited size, and quality of the studies in their review should be taken into account [12].

\section{Post-Surgical/Post-Traumatic/Scar Pain}

Acute postoperative pain is due to the surgical lesion, but in $10-50 \%$ of cases, depending upon the specific surgical procedure, the pain persists $[76,77]$. Chronic post-surgical pain usually has a neuropathic component, as a result of focal nerve damage at or around the surgical scar, and it has a considerable impact on the patient's quality of life [76]. Trauma often results in chronic post-traumatic pain as a result of nerve damage at the site of the injury [78]. In both of these conditions, the patient experiences intense pain in the innervation area of the affected peripheral nerve, which may persist for a long time and radiate to other remote sites. Additional symptoms can include allodynia, hyperalgesia, numbness, and paraesthesia.

Efficacy of the 5\% medicated plaster in treating acute post-surgical pain was demonstrated in the prospective study by Habib et al. [79] (see Table 2). Over the $24 \mathrm{~h}$ following radical retropubic prostatectomy, 


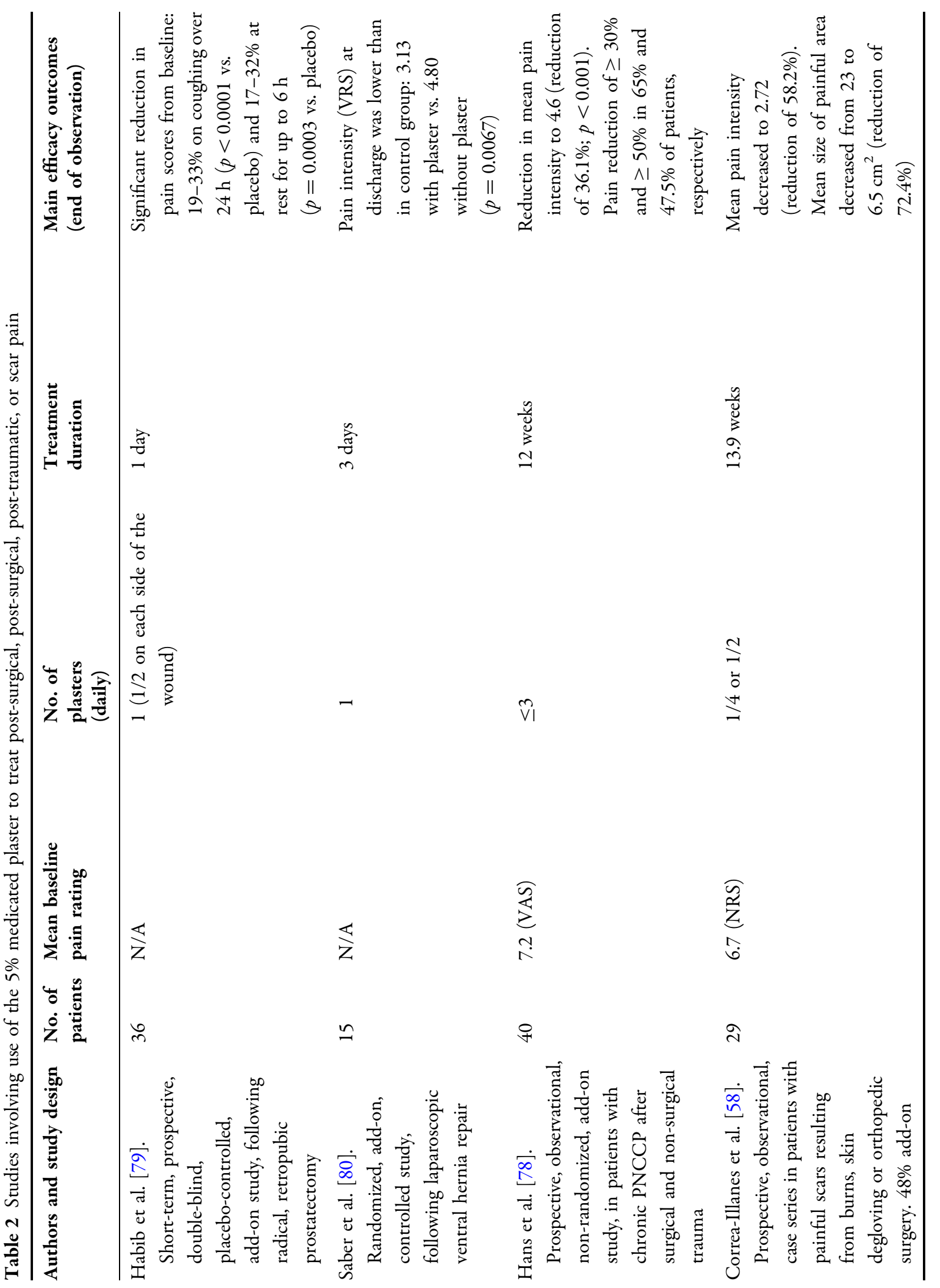




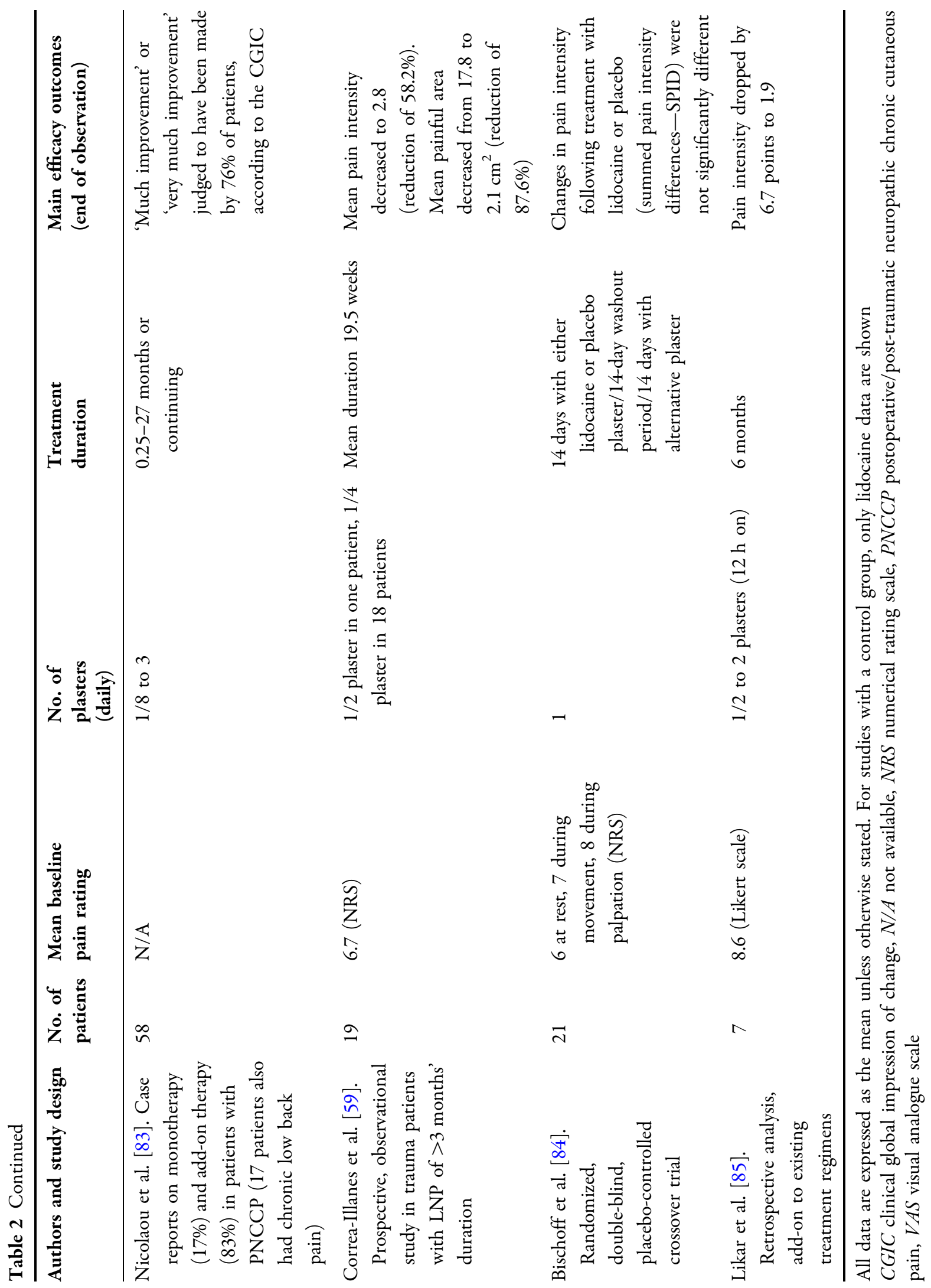


patients rated the quality of post-surgical pain control significantly better with the lidocaine plaster than with placebo $(p=0.037)$. They also reported significantly less interference with walking, deep breathing, and mood $(p<0.05)$ [79]. The retrospective study by Saber et al. involved placement of the 5\% lidocaine-medicated plaster on the anterior abdominal wall for 3 days following laparoscopic ventral herniorrhaphy [80]. The mean time to discharge was shorter in patients receiving the plaster than in controls (1.2 vs. 2.5 days; not statistically significant; $p=0.1421$ ), but the mean pain score was significantly lower $(p=0.0067$, see Table 2$)$. Two weeks after surgery, a difference in mean pain score was still apparent (2.00 vs. 2.93$)$, but was no longer statistically significant $(p=0.1245) \quad[80] . \quad$ A randomized, placebo-controlled trial in patients undergoing robotic thoracic surgery concluded that 5\% lidocaine plasters did not influence acute or persistent incisional pain, but pain scores in this study were low in both treatment groups [81]. A meta-analysis of efficacy of the plaster in acute pain management reported similar findings, but was limited by the inclusion of only five studies, potential bias from unblinded studies, clinical heterogeneity, and incomplete data regarding adjunct analgesics [82].

The use of $5 \%$ lidocaine-medicated plasters to treat chronic post-surgical and post-traumatic neuropathic pain has been evaluated in a number of studies. Post-surgical/post-traumatic neuropathic chronic cutaneous pain (PNCCP) may be a side effect of any incision of the skin following a surgical procedure or trauma [78]. One open-label, non-randomized, prospective case series of 40 patients with PNCCP reported reductions in mean pain intensity (Visual Analogue Scale or VAS) and mean Leeds
Assessment of Neuropathic Symptoms and Signs (LANSS) scores of 36.1 and 30.9\%, respectively, after 12 weeks' treatment with the lidocaine plaster (Table 2) [78]. Almost half (47.5\%) of the patients experienced a $\geq 50 \%$ reduction in pain [78]. A 2011 retrospective review evaluated 58 case reports of patients who had been treated with the lidocaine plaster for PNCCP following surgical and non-surgical trauma [83]. Clinical Global Impression of Change (CGIC) scores of 'Much Improvement' or 'Very Much Improvement' were recorded for $76 \%$ of the patients (Table 2), including all the patients (17\%) who had received the plaster as monotherapy [83]. However, lidocaine plasters did not reduce combined resting and dynamic pain ratings in 21 patients with severe, persistent inguinal postherniorrhaphy pain compared with placebo [84].

A prospective, open-label, clinical case series has investigated use of the $5 \%$ lidocaine-medicated plaster to treat neuropathic pain in scars resulting from burns, skin de-gloving or orthopedic surgery (Table 2) [58]. The mean duration of pain before starting treatment with the lidocaine plaster was 9.7 months, and the mean duration of topical treatment was 13.9 weeks. At the end of this period, the mean NRS score had decreased by $58.2 \%$ and reductions of $\geq 50 \%$ were reported by $69 \%$ of the patients [58]. Significant functional improvement was recorded by $58.6 \%$ of the patients, indicating fewer problems with walking, sleeping and normal daily activities [58]. Most notably, however, the mean size of the painful area was reduced by $72.4 \%$ - similar to that reported by Casale et al. in patients with $\mathrm{PHN}-$ and $86.2 \%$ of the patients experienced a reduction of $\geq 50 \%$ [58]. A later study by some of the same investigators evaluated the lidocaine plaster in the treatment of LNP following traumatic injury to peripheral 
nerves, over a mean period of 19.5 weeks (Table 2) [59]. The results were similar; the mean NRS score decreased by $58.2 \%$ and the mean size of the painful area decreased by $87.6 \%$, with $94.7 \%$ of the patients experiencing a reduction in size of $\geq 50 \%$ [59]. No local or systemic adverse reactions were recorded in either of these studies $[58,59]$.

The retrospective case series published by Likar et al. in 2015 includes seven patients with post-surgical/post-traumatic pain, who were observed over a period of 6 months (Table 2) [85]. All pain parameters were measured on an 11-point Likert scale $(0=$ not present to $10=$ worst possible state). At the end of the observation period, the mean pain intensity score had decreased by $78 \%$, from 8.6 at baseline to 1.9 , and no adverse events were considered to be related to the 5\% lidocaine-medicated plaster [85]. These findings are well in agreement with previous studies and case series in patients with post-surgical/post-traumatic pain [52].

\section{Wide-Ranging Reviews}

In order to provide an overview of the efficacy and safety of the 5\% lidocaine-medicated plaster in treating LNP, in 2012 Mick and Correa-Illanes reviewed 60 clinical studies (randomized, controlled or open-label with well-described methodology) dating back to 1960, as well as case reports and pharmacological studies [52]. Most related to PHN, DN or post-surgical/post-traumatic/scar pain, but other LNP conditions were also included, such as idiopathic sensory polyneuropathy, complex regional pain syndrome, and carpal tunnel syndrome sequelae. In the majority of studies, the lidocaine plaster was added to the existing analgesic regimen. The lidocaine plaster was found to be efficacious in both short-term and long-term controlled, randomized or open-label studies [52]. Patients' quality of life markedly improved in a variety of neuropathic pain conditions and pain relief was sustained over long-term treatment. The very low systemic exposure after administration meant that the plaster was very well tolerated, the most common ADRs being mild to moderate application site reactions [52]. Much of the evidence examined (in conditions other than PHN) was based on open-label studies with small sample sizes, or case reports, and the authors called for more controlled trials, but considered the lidocaine plaster may be a useful option for managing LNP, particularly in view of its excellent safety profile [52].

A later reappraisal of the clinical evidence for using the $5 \%$ medicated lidocaine plaster retrieved all relevant efficacy and safety studies (randomized, controlled, or open-label with well-described methodology), case reports and observational studies from a PubMed literature search covering the period from 1960 to September 30, 2015 [2]. Additional references were identified from published articles and the inclusion of studies was based on the methodology used, with large, well-controlled trials using appropriate statistical techniques being preferred [2]. Again, a diverse range of LNP conditions was covered in addition to PHN, $\mathrm{DN}$, and post-surgical/post-traumatic/scar pain; these included myofascial pain syndrome, cervical radiculopathy, trigeminal neuralgia, and orofacial pain. Analysis of this large volume of data suggested that the lidocaine plaster is an effective and well-tolerated treatment option in patients with LNP, and the authors noted that numerous systematic reviews included it as a first-line option for treating PHN [2]. It was found to be easy to use, improves patients' quality of life, has a good 
tolerability profile and is associated with both a lack of systemic ADRs and a low potential for drug-drug interactions [2]. Thus, it was concluded that the lidocaine plaster would appear to be indicated as the first step in the treatment of LNP either as a single agent or as a component of multimodal therapy [2].

\section{DISCUSSION}

There is mounting evidence of the efficacy of the $5 \%$ lidocaine-medicated plaster in studies conducted in everyday clinical practice, which represents a considerable proportion of actual usage. Many of these studies suggest using the lidocaine plaster as a first-line treatment for LNP, but this is not always reflected in national and international guidelines. There are various reasons for this.

Guidelines for analgesic agents are generally based on the results of randomized, double-blind, placebo-controlled clinical trials using the NNT for a defined level of pain relief as the measure of efficacy. In a review of 105 randomized, double-blind, placebo-controlled trials in patients with neuropathic pain, for example, the 5\% lidocaine-medicated plaster had an NNT of 4.4, comparable to antidepressants (1.2-6.9) and anticonvulsants (1.4-7.4) [36].

However, many trials of the lidocaine plaster used the time to withdrawal to indicate efficacy, for which it was not possible to calculate NNTs. These trials were therefore excluded when drawing up the guidelines, thereby weakening the body of evidence for the 5\% lidocaine-medicated plaster.

Furthermore, the value of NNTs in the development of guidelines is limited on several counts [2]. Firstly, reliable NNT data from multiple studies can only be obtained where these are parallel-designed, placebo-controlled studies with comparable inclusion and exclusion criteria [2, 86]. The statistical design of the lidocaine plaster trials varied from study to study, as did the maximum dose-from less than one plaster to three plasters. Secondly, NNTs are primarily derived from patients' VAS evaluations of pain, which researchers now recognize may be inappropriate, so that other criteria (patient global impression of pain improvement, psychosocial functioning, activities of daily living, gait, quality of life) are used to provide a more complete assessment of analgesic efficacy [2]. Therefore, any NNT data would have been of limited benefit. Further limitations are that non-placebo-controlled trials were excluded and efficacy was generally based on a one-dimensional measure of pain intensity or pain relief, so a statistically significant advantage could not necessarily be translated into a clinically relevant benefit.

In the case of the 2015 NeuPSIG guidelines, another consideration is that studies with an enriched enrolment design were analyzed separately, despite the fact that these can be useful in determining the efficacy of a medication compared to placebo; there appears to be no difference between enriched and non-enriched studies when measuring this parameter [87, 88]. A meta-analysis of 26 enriched enrolment, randomized withdrawal (EERW) trials in over 5000 patients with chronic non-cancer pain concluded that these trials 'if properly designed, conducted, and reported, are entirely appropriate in the context of chronic pain for explaining whether a treatment is efficacious, and for pragmatically supporting decisions over its use' [88]. Some authors have even contended that the available guidelines have very little clinical application to daily practice because 
multimodal therapy is widely considered the treatment of choice for LNP, but evidence-based data on this approach is lacking [89].

The excellent tolerability of the 5\% lidocaine-medicated plaster, its lack of ADRs, and low potential for drug-drug interactions, are widely recognized. This is a particularly important consideration when treating elderly and/or frail patients, or those receiving multiple medications. Both the EFNS and 2015 NeuPSIG guidelines recognize these benefits, stipulating that the lidocaine plaster may be considered a first-line option for these patients [13, 56]. Furthermore, its safety profile and ease of use can significantly increase patients' adherence to chronic treatment, with consequent benefits on efficacy and quality of life [33].

Taking a wider perspective, a number of studies have recorded significantly better quality of life (QoL) scores following commencement of treatment with the lidocaine plaster. For example, in one large, open-label effectiveness study in patients with PHN, the mean pain interference with QoL significantly decreased in all domains of the Brief Pain Inventory Short Form (general activity, mood, walking, working, relations, sleeping, enjoyment) after 7, 14, and 28 days' treatment $(p<0.0001)$ [70]. Similarly, when 56 patients with painful diabetic polyneuropathy were treated for 3 weeks (up to four plasters/day for $18 \mathrm{~h}$ ), significant improvements were seen in sleep quality, interference of pain with daily activities, depression, and mood [90]. More recently, a 2012 study used the QoL Impairment by Pain Inventory (QLIP) to evaluate the perceptions of over 900 patients with chronic neuropathic pain who received treatment with the lidocaine plaster [91]. QLIP measures well-being, sleep, pain, impairments, and mood, the maximum score of 40 points reflecting minimal interference with daily life.
Over the 12 weeks of the study, the mean QLIP score increased from 13.7 to 35.2 [91].

Allodynia is often a prominent feature of LNP, and is usually considered to be one of the most distressing and debilitating symptoms of PHN [92, 93]. Therefore, one contributory factor to the improved QoL scores is likely to be the reduction in the area of allodynia-typically more than 50\% $[59,60]$-produced by treatment with the lidocaine plaster. Reducing the painful area, which can increase tolerance of bathing and contact with clothing, is therefore a justifiable treatment goal for this medication. When the painful area is on the sole of the footlimiting mobility-or on the palm of the hand, this advantage of the topical route and the 5\% lidocaine-medicated plaster over systemic medications assumes even greater importance [58].

\section{CONCLUSIONS}

The 5\% lidocaine-medicated plaster has demonstrated efficacy in a variety of LNP conditions and in long-term treatment, has an excellent safety profile, does not require dose titration, and can easily be applied by the patient. On these grounds, and accepting the need for additional controlled clinical trials, it should be strongly recommended for treating LNP_either as one component of a multimodal approach or as monotherapy.

\section{ACKNOWLEDGEMENTS}

Sponsorship for this article and article processing charges were funded by Grünenthal GmbH of Aachen, Germany.

All named authors meet the International Committee of Medical Journal Editors (ICJME) 
criteria for authorship of this manuscript, take responsibility for the integrity of the work as a whole, and have given final approval to the version to be published.

Editorial assistance in the preparation of this manuscript was provided by Derrick Garwood of Derrick Garwood Ltd, Cambridge, United Kingdom. Support for this assistance was funded by Grünenthal $\mathrm{GmbH}$.

Disclosures. Ralf Baron has received grants/ research support from Pfizer, Genzyme GmbH, Grünenthal $\mathrm{GmbH}$ and Mundipharma. He is a member of the EU Project No 633491: DOLOR-isk. He is a member of the IMI "Europain" collaboration and industry members of this are: Astra Zeneca, Pfizer, Esteve, UCB-Pharma, Sanofi Aventis, Grünenthal $\mathrm{GmbH}$, Eli Lilly and Boehringer Ingelheim Pharma GmbH \& Co. KG. German Federal Ministry of Education and Research (BMBF): member of the ERA_NET NEU-RON/ IM-PAIN Project, German Research Network on Neuropathic Pain, NoPain system biology and German Research Foundation (DFG). He has received speaking fees from Pfizer, Genzyme GmbH, Grünenthal $\mathrm{GmbH}$, Mundipharma, Sanofi Pasteur, Medtronic Inc. Neuromodulation, Eisai Co. Ltd., Lilly GmbH, Boehringer Ingelheim Pharma $\mathrm{GmbH} \& \mathrm{Co}$. KG, Astellas, Desitin, Teva Pharma, Bayer-Schering, MSD GmbH, and Seqirus. He has been a consultant for Pfizer, Genzyme $\mathrm{GmbH}$, Grünenthal $\mathrm{GmbH}$, Mundipharma, Allergan, Sanofi Pasteur, Medtronic Inc. Neuromodulation, Eisai Co. Ltd., Lilly $\mathrm{GmbH}$, Boehringer Ingelheim Pharma GmbH \& Co. KG, Astellas, Novartis, Bristol-Myers-Squibb, Biogenidec, AstraZeneca, Merck, AbbVie, Daiichi Sankyo, Glenmark Pharmaceuticals, Seqirus, Teva Pharma, Genentech, and Galapagos NV.
Massimo Allegri has received honoraria from Angelini, CareFusion, Grünenthal $\mathrm{GmbH}$, MSD, and Mundipharma, and a research grant from the European Union. Gerrardo Correa-Illanes has acted as a medical advisor to Grünenthal GmbH, LATAM Airlines Group, and Global. Guy Hans has nothing to disclose. Michael Serpell has received honoraria from Astellas, Grünenthal GmbH, NAPP, and Pfizer for speaking at meetings. His institution has received research support in the past 5 years from commercial studies sponsored by Astellas, Grünenthal GmbH, and NAPP. Gerard Mick has received honoraria from Grünenthal GmbH, Mundipharma, Pfizer and Astellas. Victor Mayoral has received honoraria and fees for the provision of expert opinion from Grünenthal $\mathrm{GmbH}$, Mundipharma, Menarini, Archimedes Pharma, Takeda and Ferrer.

Compliance with Ethics Guidelines. This article is based on previously conducted studies and does not involve any new studies of human or animal subjects performed by any of the authors.

Data Availability. Data sharing is not applicable to this article as no datasets were generated or analyzed during the current study.

Open Access. This article is distributed under the terms of the Creative Commons Attribution-NonCommercial 4.0 International License (http://creativecommons.org/licenses/ by-nc/4.0/), which permits any noncommercial use, distribution, and reproduction in any medium, provided you give appropriate credit to the original author(s) and the source, provide a link to the Creative Commons license, and indicate if changes were made. 


\section{REFERENCES}

1. Mick G, Correa-Illanes C. Topical pain management with the 5\% lidocaine-medicated plaster-a review. Curr Med Res Opin. 2012;28(6):937-51.

2. de Leon-Casasola OA, Mayoral V. The topical 5\% lidocaine-medicated plaster in localized neuropathic pain: a reappraisal of the clinical evidence. J Pain Res. 2016;9:67-79.

3. Campbell BJ, Rowbotham M, Davies PS, Jacob P, BenoWitz NL. Systemic absorption of topical lidocaine in normal volunteers, patients with post-herpetic neuralgia, and patients with acute herpes zoster. J Pharm Sci. 2002;91:1343-50.

4. Stanos SP, Galluzzi KE. Topical therapies in the management of chronic pain. Postgrad Med. 2013;125(4 Suppl 1):25-33.

5. Brennan MJ. The clinical implications of cytochrome p450 interactions with opioids and strategies for pain management. J Pain Symptom Manage. 2012;44(6 Suppl):S15-22.

6. Argoff CE, Katz N, Backonja M. Treatment of postherpetic neuralgia: a review of therapeutic options. J Pain Symptom Manag. 2004;28(4):396-410.

7. Jorge LL, Feres CC, Teles VEP. Topical preparations for pain relief: efficacy and patient adherence. J Pain Res. 2011;4:11-24.

8. Dworkin $\mathrm{RH}, \mathrm{O}^{\prime}$ Connor $\mathrm{AB}$, Backonja $\mathrm{M}$, et al. Pharmacologic management of neuropathic pain: evidence-based recommendations. Pain. 2007;132(3):237-51.

9. Garnock-Jones KP, Keating GM. Lidocaine 5\% medicated plaster. A review of its use in postherpetic neuralgia. Drugs. 2009;69:2149-65.

10. O'Connor AB, Dworkin RH. Pharmacologic management of neuropathic pain: an overview of recent guidelines. Am J Med. 2009;122(10 Suppl):S22-32.

11. Dworkin RH, $\mathrm{O}^{\prime}$ Connor $\mathrm{AB}$, Audette J, et al. Recommendations for the pharmacological management of neuropathic pain: an overview and literature update. Mayo Clin Proc. 2010;85(Suppl 3):S3-14.

12. Wolff RF, Bala MM, Westwood M, Kessels AG, Kleijnen J. 5\% lidocaine-medicated plaster in painful diabetic peripheral neuropathy (DPN): a systematic review. Swiss Med Wkly. 2010;140:297-306.
13. Attal N, Cruccu G, Baron R, et al. EFNS guidelines on the pharmacological treatment of neuropathic pain: 2010 revision. Eur J Neurol. 2010;17:1113-23.

14. Harden RN, Kaye AD, Kintanar T, Argoff CE. Evidence-based guidance for the management of postherpetic neuralgia in primary care. Postgrad Med. 2013;125(4):191-202.

15. Allegri M, Baron R, Hans G, et al. A pharmacological treatment algorithm for localized neuropathic pain. Curr Med Res Opin. 2016;32(2):377-84.

16. Baron R, Mayoral V, Leijon G, Binder A, Steigerwald I, Serpell M. Efficacy and safety of 5\% lidocaine (lignocaine) medicated plaster in comparison with pregabalin in patients with postherpetic neuralgia and diabetic polyneuropathy. Clin Drug Invest. 2009;29(4):231-41.

17. Navez ML, Monella C, Bösl I, Sommer D, Delorme C. 5\% lidocaine-medicated plaster for the treatment of postherpetic neuralgia: a review of the clinical safety and tolerability. Pain Ther. 2015;4:1-15.

18. Varrassi G, Müller-Schwefe G, Pergolizzi J, et al. Pharmacological treatment of chronic pain - the need for CHANGE. Curr Med Res Opin. 2010;26(5):1231-45.

19. Schumacher C, Glosner SE. Assessment of pain and impact of care among patients with painful diabetic peripheral neuropathy. J Am Pharm Assoc. 2014;54(1):14-8.

20. Breivik H, Collett B, Ventafridda V, Cohen R, Gallacher D. Survey of chronic pain in Europe: prevalence, impact on daily life, and treatment. Eur J Pain. 2006;10:287-333.

21. Sacks GM. Unmet need in the treatment of postherpetic neuralgia. Am J Manag Care. 2013;19:S207-13.

22. Persaud N, Strichartz GR. Micromolar lidocaine selectively blocks propagating ectopic impulses at a distance from their site of origin. Pain. 2002;99:333-40.

23. Chevrier P, Vijayaragavan K, Chahine M. Differential modulation of Nav1.7 and Nav1.8 peripheral nerve sodium channels by the local anesthetic lidocaine. $\mathrm{Br} \mathrm{J}$ Pharmacol. 2004;142(3):576-84.

24. Krumova EK, Zeller M, Westermann A, Maier C. Lidocaine patch $(5 \%)$ produces a selective, but incomplete block of $\mathrm{A} \delta$ and $\mathrm{C}$ fibers. Pain. 2012;153(2):273-80.

25. Wasner G, Kleinert A, Binder A, Schattschneider J, Baron R. Postherpetic neuralgia: topical lidocaine is 
effective in nociceptor-deprived skin. J Neurol. 2005;252(6):677-86.

26. Shiga M, Nishina K, Mikawa K, Obara H. The effects of lidocaine on nitric oxide production from an activated murine macrophage cell line. Anesth Analg. 2001;92:128-33.

27. Tanaka A, Minoguchi K, Oda N, et al. Inhibitory effect of lidocaine on $\mathrm{T}$ cells from patients with allergic asthma. J Allergy Clin Immunol. 2002;109:485-90.

28. Jara-Oseguera A, Simon SA, Rosenbaum T. TRPV1: on the road to pain relief. Curr Mol Pharmacol. 2008;1(3):255-69.

29. Electronic medicines compendium. Versatis 5\% medicated plaster. Summary of Product Characteristics. Available at: https:// www.medicines.org.uk/emc/medicine/19291. Last Accessed April 29, 2016.

30. Likar R, Kagar I, Obmann M, Pipam W, Sittl R. Treatment of localized neuropathic pain after disk herniation with 5\% lidocaine-medicated plaster. Int J Gen Med. 2012;5:689-92.

31. Gammaitoni AR, Alvarez NA, Galer BS. Pharmacokinetics and safety of continuously applied lidocaine patches 5\%. Am J Health Syst Pharm. 2002;59(22):2215-20.

32. Delorme C, Navez ML, Legout V, Deleens R, Moyse D. Treatment of neuropathic pain with $5 \%$ lidocaine-medicated plaster: five years of clinical experience. Pain Res Manag. 2011;16(4):259-63.

33. Sabatowski R, Hans G, Tacken I, Kapanadze S, Buchheister B, Baron R. Safety and efficacy outcomes of long-term treatment up to 4 years with $5 \%$ lidocaine-medicated plaster in patients with post-herpetic neuralgia. Curr Med Res Opin. 2012;28:1337-46.

34. Galer BS, Gammaitoni AR. More than 7 years of consistent neuropathic pain relief in geriatric patients. Arch Intern Med. 2003;163(5):628.

35. Treede RD, Jensen TS, Campbell JN, et al. Neuropathic pain: redefinition and a grading system for clinical and research purposes. Neurology. 2008;70:1630-5.

36. Finnerup NB, Haroutounian S, Kamerman P, et al. Neuropathic pain: an updated grading system for research and clinical practice. Pain. 2016;157(8): 1599-606.

37. Torrance N, Smith BH, Bennett MI, Lee AJ. The epidemiology of chronic pain of predominantly neuropathic origin: results from a general population survey. J Pain. 2006;7:281-9.
38. Bouhassira D, Lanteri-Minet M, Attal N, Laurent B, Touboul C. Prevalence of chronic pain with neuropathic characteristics in the general population. Pain. 2008;136:380-7.

39. Baron R. Neuropathic pain-a clinical perspective. Nat Clin Pract Neurol. 2006;2:95-106.

40. Truini A, Garcia-Larrea L, Cruccu G. Reappraising neuropathic pain in humans - how symptoms help disclose mechanisms. Nat Rev Neurol. 2013;9:572-82.

41. Marchettini P. The burning case of neuropathic pain wording. Pain. 2005;114:313-4.

42. Baron R, Binder A, Wasner G. Neuropathic pain: diagnosis, pathophysiological mechanisms, and treatment. Lancet Neurol. 2010;9(8):807-19.

43. Fields HL, Rowbotham M, Baron R. Postherpetic neuralgia: irritable nociceptors and deafferentation. Neurobiol Dis. 1998;5:209-27.

44. Andersen G, Vestergaard K, Ingeman-Nielsen M, Jensen TS. Incidence of central post-stroke pain. Pain. 1995;61:187-93.

45. Finnerup NB, Johannesen IL, Sindrup SH, Bach FW, Jensen TS. Pain and dysesthesia in patients with spinal cord injury: a postal survey. Spinal Cord. 2001;39:256-62.

46. Österberg A, Boivie J, Thuomas KA. Central pain in multiple sclerosis - prevalence and clinical characteristics. Eur J Pain. 2005;9:531-5.

47. Haanpää $M$, Backonja $M$, Bennett $M$, et al. Assessment of neuropathic pain in primary care. Am J Med. 2009;122:S13-21.

48. Attal N, Lanteri-Minet M, Laurent B, Fermanian J, Bouhassira D. The specific disease burden of neuropathic pain: results of a French nationwide survey. Pain. 2011;152:2836-43.

49. Smith BH, Torrance N. Epidemiology of neuropathic pain and its impact on quality of life. Curr Pain Headache Rep. 2012;16:191-8.

50. Freynhagen R, Baron R, Gockel U, Tollë TR. painDETECT: a new screening questionnaire to identify neuropathic components in patients with back pain. Curr Med Res Opin. 2006;22:1911-20.

51. Bouhassira D, Letanoux M, Hartemann A. Chronic pain with neuropathic characteristics in diabetic patients: a French cross-sectional study. PLoS One. 2013;8(9):e74195.

52. Mick G, Baron R, Finnerup NB, et al. What is localized neuropathic pain? A first proposal to 
characterize and define a widely used term. Pain Manage. 2012;2(1):71-7.

53. Dubinsky RM, Kabbani H, El-Chami Z, Boutwell C, Ali H. Practice Parameter: Treatment of postherpetic neuralgia. An evidence-based report of the Quality Standards Subcommittee of the American Academy of Neurology. Neurology. 2004;63(6):959-65.

54. Attal N, Finnerup NB. Pharmacological management of neuropathic pain. Pain Clin Updates. 2010;18(9):1-8.

55. Attal N, Cruccu G, Haanpää $M$, et al. EFNS guidelines on pharmacological treatment of neuropathic pain. Eur J Neurol. 2006;13:1153-69.

56. Finnerup NB, Attal N, Haroutounian S, et al. Pharmacotherapy for neuropathic pain in adults: a systematic review and meta-analysis. Lancet Neurol. 2015;14:162-73.

57. Guyatt GH, Oxman AD, Vist GE, et al. GRADE: an emerging consensus on rating quality of evidence and strength of recommendations. BMJ. 2008;336(7650):924-6.

58. Correa-Illanes G, Calderón W, Roa R, Piñeros JL, Dote J, Medina D. Treatment of localized post-traumatic neuropathic pain in scars with $5 \%$ lidocaine-medicated plaster. Local Reg Anesth. 2010;3:77-83.

59. Correa-Illanes G, Roa R, Piñeros JL, Calderón W. Use of $5 \%$ lidocaine-medicated plaster to treat localized neuropathic pain secondary to traumatic injury of peripheral nerves. Local Reg Anesth. 2012;5:47-53.

60. Casale R, Di Matteo M, Minella CE, Fanelli G, Allegri M. Reduction of painful area as new possible therapeutic target in post-herpetic neuropathic pain treated with 5\% lidocaine-medicated plaster: a case series. J Pain Res. 2014;7:353-7.

61. Johnson RW, Bouhassira D, Kassianos G, Leplège A, Schmader KE, Weinke T. The impact of herpes zoster and post-herpetic neuralgia on quality-of-life. BMC Med. 2010;8:37.

62. Oster G, Harding G, Dukes E, Edelsberg J, Cleary PD. Pain, medication use, and health-related quality of life in older persons with postherpetic neuralgia: results from a population-based survey. J Pain. 2005;6:356-63.

63. Johnson RW, McElhaney J. Postherpetic neuralgia in the elderly. Int J Clin Pract. 2009;63(9):1386-91.

64. Galer BS, Rowbotham MC, Perander J, Friedman E. Topical lidocaine patch relieves postherpetic neuralgia more effectively than a vehicle topical patch: results of an enriched enrollment study. Pain. 1999;80(3):533-8.

65. Binder A, Bruxelle J, Rogers P, Hans G, Bösl I, Baron R. Topical 5\% lidocaine (lignocaine) medicated plaster treatment for post-herpetic neuralgia: results of a double-blind, placebo-controlled, multinational efficacy and safety trial. Clin Drug Investig. 2009;29(6):393-408.

66. Rehm S, Binder A, Baron R. Post-herpetic neuralgia: $5 \%$ lidocaine-medicated plaster, pregabalin, or a combination of both? A randomized, open, clinical effectiveness study. Curr Med Res Opin. 2010;26:1607-19.

67. Wolff RF, Bala MM, Westwood M, Kessels AG, Kleijnen J. 5\% lidocaine-medicated plaster vs other relevant interventions and placebo for post-herpetic neuralgia (PHN): a systematic review. Acta Neurol Scand. 2011;123(5):295-309.

68. Caldwell DM, Ades AE, Higgins JPT. Simultaneous comparison of multiple treatments: combining direct and indirect evidence. BMJ. 2005;331:897.

69. Helgason S, Petursson G, Gudmundsson S, Sigurdsson JA. Prevalence of postherpetic neuralgia after a first episode of herpes zoster: prospective study with long term follow up. BMJ. 2000;321:794-6.

70. Katz NP, Gammaitoni AR, Davis MW, Dworkin RH. Lidoderm Study Group. Lidocaine patch 5\% reduces pain intensity and interference with quality of life in patients with postherpetic neuralgia: an effectiveness trial. Pain Med. 2002;3:324-32.

71. Pickering G, Pereira $B$, Clère $F$, et al. Cognitive function in older patients with postherpetic neuralgia. Pain Pract. 2014;14:E1-7.

72. Dyck PJ, Katz KM, Karnes JL, et al. The prevalence by staged severity of various types of diabetic neuropathy, retinopathy and nephropathy in a population-based cohort, the Rochester Diabetic Neuropathy Study. Neurology. 1993;43:817-24.

73. Van Acker K, Bouhassira D, De Bacquer D, et al. Prevalence and impact on quality of life of peripheral neuropathy with or without neuropathic pain in type 1 and type 2 diabetic patients attending hospital outpatients clinics. Diabetes Metab. 2009;35:206-13.

74. White WT, Patel N, Drass M, Nalamachu S. Lidocaine patch 5\% with systemic analgesics such as gabapentin: a rational polypharmacy approach for the treatment of chronic pain. Pain Med. 2003;4:321-30. 
75. Argoff CE, Galer BS, Jensen MP, Oleka N, Gammaitoni AR. Effectiveness of the lidocaine patch $5 \%$ on pain qualities in three chronic pain states: assessment with the Neuropathic Pain Scale. Curr Med Res Opin. 2004;20(Suppl 2):S21-8.

76. Macrae WA. Chronic post-surgical pain: 10 years on. Br J Anaesth. 2008;101:77-86.

77. Shipton E. Post-surgical neuropathic pain. ANZ J Surg. 2008;78:548-55.

78. Hans G, Joukes E, Verhulst J, Vercauteren M. Management of neuropathic pain after surgical and non-surgical trauma with lidocaine 5\% patches: study of 40 consecutive cases. Curr Med Res Opin. 2009;25:2737-43.

79. Habib AS, Polascik TJ, Weizer AZ, et al. Lidocaine patch for postoperative analgesia after radical retropubic prostatectomy. Anesth Analg. 2009;108:1950-3.

80. Saber AA, Elgamal MH, Rao AJ, Itawi EA, Martinez RL. Early experience with lidocaine patch for postoperative pain control after laparoscopic ventral hernia repair. Int J Surg. 2009;7:36-8.

81. Vrooman B, Kapural L, Sarwar S, et al. Lidocaine 5\% patch for treatment of acute pain after robotic cardiac surgery and prevention of persistent incisional pain: a randomized, placebo-controlled, double-blind trial. Pain Med. 2015;16(8):1610-21.

82. Bai Y, Miller T, Tan M, Law LS, Gan TJ. Lidocaine patch for acute pain management: a meta-analysis of prospective controlled trials. Curr Med Res Opin. 2015;31(3):575-81.

83. Nicolaou A, Nicholson B, Hans G, Brasseur L. Outcome predictors for treatment success with $5 \%$ lidocaine-medicated plaster in low back pain with neuropathic components and neuropathic pain after surgical and nonsurgical trauma. J Pain Res. 2011;4:25-38.

84. Bischoff JM, Petersen M, Uçeyler N, Sommer C, Kehlet H, Werner MU. Lidocaine patch (5\%) in treatment of persistent inguinal postherniorrhaphy pain: a randomized, double-blind, placebo-controlled, crossover trial. Anesthesiology. 2013;119(6):1444-52.
85. Likar R, Demschar S, Kager I, Neuwersch S, Pipam W, Sittl R. Treatment of localized neuropathic pain of different etiologies with the 5\% lidocaine-medicated plaster - a case series. Int J Gen Med. 2015;8:9-14.

86. Finnerup NB, Otto M, McQuay HJ, Jensen TS, Sindrup SH. Algorithm for neuropathic pain treatment: an evidence-based proposal. Pain. 2005;118:289-305.

87. Furlan AD, Chaparro LE, Irvin E, Mailis-Gagnon A. A comparison between enriched and nonenriched enrollment randomized withdrawal trials of opioids for chronic noncancer pain. Pain Res Manag. 2011;16(5):337-51.

88. Moore RA, Wiffen PJ, Eccleston C, et al. Systematic review of enriched enrolment, randomised withdrawal trial designs in chronic pain: a new framework for design and reporting. Pain. 2015;156(8):1382-95.

89. de Leon-Casasola O. New developments in the treatment algorithm for peripheral neuropathic pain. Pain Med. 2011;12(Suppl 3):S100-8.

90. Barbano RL, Herrmann DN, Hart-Gouleau S, Pennella-Vaughan J, Lodewick PA, Dworkin RH. Effectiveness, tolerability, and impact on quality of life of the $5 \%$ lidocaine patch in diabetic polyneuropathy. Arch Neurol. 2004;61(6):914-8.

91. Überall MA, Müller-Schwefe GH. Patient perceptions associated with the 5\% lidocaine-medicated plaster in daily practice. Curr Med Res Opin. 2012;28(6):901-9.

92. Johnson RW, Wasner G, Saddier P, Baron R. Herpes zoster and postherpetic neuralgia: optimizing management in the elderly patient. Drugs Aging. 2008;25:991-1006.

93. Buonocore M, Gatti AM, Amato G, Aloisi AM, Bonezzi C. Allodynic skin in post-herpetic neuralgia: histological correlates. J Cell Physiol. 2012;227(3):934-8. 